\title{
Psychodynamic prototype through personality organization chart of educational leaders
}

\section{DOI: http://doi.org/10.26758/8.1.12}

Silva Ibrahimi (1), Eglantina Dervishi (2), Valbona Muca (3), Marije Dobra (4)

(1) Department of Psychology, "Albanian University", Tirana, Albania

(2) Department of Psychology and Pedagogy, Faculty of Social Sciences, University of Tirana, Tirana, Albania

(3) Department of Social Work, Faculty of Education “Aleksander Xhuvani”, University of Elbasan, Albania

(4) Local Police Department of Tirana, Albania

Address correspondence to: Silva Ibrahimi, Departament of Psychology, "Albanian University", Tirana, Albania, e-mail: silva.ibrahimi@yahoo.it

\begin{abstract}
Objectives. The present study aims to explore the problematic situation of Personality Organization and Behavioral Tendency in the target group of school leaders and to highlight the need of a qualitative change and organizational structures of the preventive evaluation of mental health in school. We aim to describe the utility of a novel Mental Health Taxonomy as the Psychodynamic Manual as an overall taxonomy rather than the DSM or ICD.

Material and methods. The research was conducted through the interweaving of literature with the context operationalization. In its initial phase of the study, we considered a wide range of classic literature and contemporary updates on elements of human personality, maladaptive or adaptive structures, educational leadership and their typologies. Through a quantitative and qualitative methodology as Q methodology, we reached to fulfill the presented aims and goals. Supporting instruments for the operationalization of the method were: Psychodiagnostic Chart, Mental Functional Level Questionnaire, Object Relations Inventory and the Functional Assessment of Ego.

Results. The study showed that there is not only a strong positive relationship between Pathogenic Beliefs and Personality Organization (but also that teachers and school principals display increasing symptoms of "maladaptive behavioral tendency". Leaders with high levels of Neurotic Personality Organization, which has the highest frequency in the factor weight of the mental component have also higher chances for coercive behavior than leaders with Borderline Personality Organization. Results were analyzed with PQMethod software processor.

Conclusions. At the end of the article, we outline some suggestions for formation of a structured based assessment of psychological problems supporting leaders in schools, the function role style and leadership in supporting education and health.
\end{abstract}

Keywords: psychodynamic prototype, personality organization, psychodiagnostic chart; continuing education. 


\section{Introduction}

Psychoanalysis is probably one of the most important theories and methods of approaching, understanding and analyzing the development of emotional functions, motivation, and drives in the human psychology. Endeavors to define a normal and abnormal personality have not set a distinction between what is a tendency of a personality illness state and a clear mental illness. Approaching psychoanalysis to schools as a denotative of problems or conflict resolution, between self and others, was early defined in the literature.

Dynamic forces in the cases where a greater psychic engagement is required are more unconscious than conscious.

The advantage of evaluating a suitable personality level (healthy) of a/the leader is, of course, one of "the bells falling harder" in terms of a progressive adaptation of our transitional society to globalization and changing contexts.

For a scientific clinical screening and prevention of events when maladaptive behavior as violence, persecution and abuse cacturn in prevailing and on hard consequences for the future, it is important to have a clear view of the situation. It helps in this context the supporting evidence-based psychodynamic literature on "Objects Relations", "Personality Pattern and Organization" and "Personality Prototype". Researchers and clinicians from all over the world who contributed in collecting data for instrument validation and their impressions were very important in realizing a database for the newest version of the Psychodynamic Diagnostic Chart -2 (Gordon and Bornstein, 2015; Gordon and Bornstein, 2017). At the center of the concept of classical psychoanalysis in the organization of psyche is the existence of an energetic principle, id, in which is required an immediate dismissal of inner satisfaction and evolution of a well-structured ego. The ego, appropriately, has come as a result of contact between the energy of the id psyche and external realities (Freud, 1900, 1923, 1933).

It is very important for researchers to implement innovative methodologies in order to not reinforce positively the same opinion more than twice and to not affect subjects with controversary dichotomic statements (McKeown and Thomas, 1988).

Ego drives interact in a dynamic mode with each other and defense mechanisms as repression lay to defend infantile satisfaction that the drives unconsciously carry. Unconscious mental life is regulated automatically by the pleasure and desire of pain principle beyond the control of Ego and away from thoughts, beliefs or reality. Ego-repression in the unconscious terms could be adjusted by the assessment of danger and safety. This adjustment is not automatic but is carried out by the high mental functions (thoughts, anticipations, and judgments).

The powerful feelings of fear, anxiety or guilt are also displayed. The experiences from which a child acquires unconscious beliefs are in themselves traumatic.

Such experiences might be objectively unresponsive (the case of little Hans - Freud, 1909) and subjectively traumatic. In the late theory, psychopathology arises from unconscious beliefs to infantile traumatic experiences. Thus, the later adult represses libidinal impulses and then fixes them. Repression is regulated unconsciously by the criteria of safety and risk and the person decides if he could experience freely a component by the whole content of repressed cognitions and further adjust it bringing into conscience. The censor ego regulates the expression of impulses by the criteria of safety and danger and other pulsions manifested in dreams as the power of the dreamer is closed when he/she is sleeping. According to Freud's late papers, psychopathology derives by pathogenic beliefs and the castration anxiety in cathexis (Freud, 1914). 
The consequences of unconscious conflicts demand the analysis of the wholeness withn the three specific parts. In the theory of Object Relations, implications of the structural theory (dissolving unconscious conflicts among impulses and mechanisms of defense) have changed as unconscious conflicts are internalized into objects relations.

Such relations define the nature of defensive actions and impulses toward objects or other relations. Internalized object relationships are the foundation of the tripartite patterns as id, ego, and superego. In a deeper research for the development of the pattern of relations between the individual and others, the Kleinian fellows argued some other viewpoints concerning object-relations model (Klein, 2002)

The core unit was the self in relation to another - and the nature of the relationship between them. Human unit in the external world, involve essentially, relations with other. In the psychology of inner dynamics, self must be understood as always existing and according to relationships it has, remembers, wishes or creates. In the relational and structural model, the shape of self grows and changes from the experiences in their relations, whereas, the nature of the relations is developed and altered by the self.

The unit of self, other and relation turn into a model for the comprehension of shape in every subsystem within the self. Neuroses are seen as related to the poor resolution of the Oedipal Complex. Freud (1917-1957) argued that object relations are a mean of continuing to receive gratification by internalizing images of love after a loss. In the field of personality pattern and organization, defense mechanisms to distortion and the Overall Defense Function have an alternation in the depressive episodes, self-destructing symptoms, and the reversible suicide ideation.

The combination between idealization and disintegration of a given structure makes leader find new alternative models to avoid the threat. The invested energy directs toward the antilibidinal object, destruction in another time of this antilibidinal self by the internal pathogenic patterns.

If we recall the psychosocial phenomena of verbal, physical, emotional or psychological abuse reported in the media throughout this time, the school and community were often encountered students abuse. In a broader view, we could imply that the role of school as an instructive and organizational institution has changed with time either from the mental representation, which has been offered to students in these transition years, or by the internalization of the leader role. At this point the student manifest his or her antilibido in relation to the teacher; teacher attracts the antilibidinal energy and based on his/her personality patterns derives it to the director and then to community shaping a cyclic behavioral tendency.

If this behavioral tendency is placed for instance, in the parameters of a personality affected by stress or neurotic, the resultant will develop a leader personality with a neurotic level that under the influence even of a small stimulus will generate violence or dysphoric outburst.

It is important therefore to understand, monitor and prevent the maladaptive behavioral tendency since its beginning and to avoid an internalization that could forward ego at an earlier state of "trans". The creation of structures involves the separation of self and repression of that part which dissolves from the whole.

Repression is the key component in the endopsychic structure as it represents the mechanism of self -division. The experience integrated within self may be manifested in memory or in a gradual alternation of the wholeness self. Unless the experience is not integrated when it is so not well tolerated to come into awareness, it may be a subject or repression.

Seeking for a maladaptive behavioral trend is surely an endeavor but also crucial for prevention and intervention in the clinical context. The more predictable a behavior, the greater the 
prevention. Since the early writings of Freud, maladaptive behavior took a special attention as it is the prelude of "all sins"(Freud, 1930).

\section{Material and methods}

The method used in the present study aimed to reach a validation since the preliminary assessment of Q method and its suitability to the context with 100 participants. Q methodology was scientifically introduced in 1935 by the British psychiatrist and psychologist William Stephenson and is often associated with a quantitative analysis toward factorial analysis. What is referred today as a Q methodology was introduced for the first time in the Journal "Nature" by the physician and psychologist William Stephenson in 1935. Stephenson served at the time as the assistant of Charles Spearman, the inventor of factorial analysis. The term Q methodology to Brown is further explained in the article "Q Technique and Questionnaires". In recent days, Q methodology is widely used in social sciences, nursing and medical sciences, behavioral medicine and especially in psychology (Stainton Rogers et al., 1995).

For the first in Albania, as a mixed research methodology, Q-sort was used in the research study "Q-sort and Study Case Psychoanalysis" (Ibrahimi \& Qirjako, 2011). In the present research, we were based on the empirical data revealed in the 2011 and the preliminary data collected in the pre-test conducted in Albania, in 2015 by Ibrahimi and Gordon. Our core research question focused on a definition of a trending behavior and personality organization level of School Leaders in Albania. Data of significance alpha $(\mathrm{n}=100 ;=.835)$ revealed a strong correlation between the assessment of viewpoints for personality and leadership in Q method. Correlations between Pearson variables revealed a positive correlation among variables (teachers and directors) and statements related to the personality and leadership style (Q.2, Q.5, Q.24).

In the present study, we have designed a starting concourse of 100 statements in the preliminary phase that were reduced to 77 in the final phase of the test. As Q is focused on the correlation of responses of the individual, statements were designed for both categories of leaders "teachers" and "directors of educational institution" in a tot of 154 statements. Each test holds statements constructed to measure Personality Level, the Influence of School Environment and Community and Leadership Style of the individual according to their functions. Selection of the participants in the study was conducted according to the evidence for the geographic and school population distribution by the Institute of Developing Education with School Directories and the pedagogical staff. We cared that the aging, gender, demographic, education experience of the participants to be very different even within schools of the same city.

Collected data were initially added to the dataset of $\mathrm{Q}$ divided for each unit. Further, through Q software, there were designed the orthogonal variables and matrices among subjects.

Records of statements constructs were gathered by the literature review of "Object Relations" and "Personality Level", research and scientific articles on the practices of teaching and learning, resource data from chronicles related to school leadership and records widely reported in media for school situation and teachers in the Albanian context.

\section{Results}

In both extremities of distribution, there was a position of statements from the most characteristic (on the right) to the least characteristic (to the left). The data gathered on stability and significance in test helped us in designing the final test $\mathrm{Q}$ in two versions, for teachers and school directors with a definitive number of statements 77. In the present study (preliminary phase) 
participants chose statements in a distribution of $3,5,8,12,16,18,16,12,8,5,3$.As the subject had compiled the Q-sort, we recorded the number of ranked statements in a matrix.

Data of significance alpha $(n=50 ;=.835)$ revealed a strong correlation between the assessment of viewpoints for personality and leadership in Q method. Correlations between Pearson variables revealed a positive correlation among variables (teachers and directors) and statements related to the personality and leadership style (Q.2, Q.5, Q.24). Factorial analysis for all 50 subjects reported the creation of 17 factors from which 4 were considered stable on a level of 0.75 0.85.These factors were considered significant and were reported for the further pyramidal distribution Q.

Sample selection in $\mathrm{Q}$ is not contained to random but some defined criteria as it is linked to the aim and statements introduced in Q (McKeown and Thomas, 1988, pp.37). Significant data were revealed by the comparison of P-model, which represents the Personality Pattern and Disorders of each participant in a study. Every single individual in the P-pattern holds a personal experience or view related to the matrix of Q-sort combination (Brown, 1980).

Participants in the study, who were first contacted in the preliminary phase in March 2014, were introduced with the possibility to participate in the full testing in 2015.

We could detect various types of personality organization, maladaptive behavioral tendency, emotional-behavioral reactions, relatedeness to other, the level of affect and attachment for every personality prototype.

According to the PQMethod, statements related to the element of "Maladaptive Behavior" have obviously a prevailing place over other statements as they carry the greatest weight in the aim of the present study. Descriptive data revealed an altered medium in our cities. Thus, for instance, in Shkoder the highest rank (z-score) is achieved in the statement no.67 of the Q-test "When others gaze me, I flush and think..."with a scoring of 1,819.

Weighting variable matrices and ranking of rotated factors were conducted for each respondent. A relatively small portion of respondents $(14 \%)$ expressed a neutral attitude in characterizing behavior (assessed 0) whereas the majority of them referred significant differences in behavioral trend. From testing the reliability of participants, validation for the Overall Personality Organization scale was $.92(\mathrm{p}<.001)$; for the Overall Severity and Personality Disorder was .89 ( $\mathrm{p}<.001$ ); for the 9 capacities of Mental Functioning ranges from .77 to .89 ( $\mathrm{p}<.001$ ); and for Severity of Symptoms was .87 ( $\mathrm{p}<.001)$. All the PDC constructs revealed strong correlations with MMPI-2 scores (Gordon and Stoffey, 2016). The MMPI-2 scales for Schizophrenia (Sc), Hysteria (Hy) and Ego Strength (Es) revealed a good validity for categorical components of the levels of Psychotic, Borderline and Neurotic Personality Organization.

These categorical components were collected by dividing in 10 points the scale of Personality Organization: psychotic (ratings 1-3, no. = 13), borderline (ratings 4-6, no. = 52) and neurotic (ratings $7-10$, no. $=33$.For the psychotic level scale, authors predicted a significantly higher mean than both $\mathrm{Hy}$ and Es scales. From the pairwise comparison data was revealed that Sc is significantly higher than Es $(\mathrm{M}=85.77, \mathrm{SD}=19.55$ vs. $34.31, \mathrm{SD}=6.78, \mathrm{p}=.001)$ and slightly higher than Hy $(\mathrm{M}=85.77, \mathrm{SD}=19.55$ vs. $72.69, \mathrm{SD}=18.46, \mathrm{p}=.017)$.

For the borderline level scale, authors predicted that the means of the scales Sc and Hy should not be significantly different but both should be significantly higher than the mean of Es.

$\mathrm{Sc}$ and Hy are not very different but $\mathrm{Sc}$ is much higher than $\mathrm{Es}(\mathrm{M}=62.21, \mathrm{SD}=12.31$, vs. 43.58, $\mathrm{SD}=10.25, \mathrm{p}=.001)$ and $\mathrm{Hy}$ is much higher than $\mathrm{Es}(64.21, \mathrm{SD}=12.31$ vs. $43.58, \mathrm{SD}=10.25, \mathrm{p}=$ .001). For the neurotic level scale, it was predicted that the scales Es, Sc and Hy had an average distribution and that Ego Strength was oriented to the normal distribution. 
We can define in this line the strength of Ego functioning in terms of a tendency of Personality towards illness. If, for example, a leader with a Depressive Personality would live in an isolated social environment for a certain time, he/she is more likely to develop the complete range of symptoms of Major Depression.

Table.1. Correlations for the 7 Elements of the Overall Personality Organization Scale.

\begin{tabular}{|l|c|c|c|}
\hline Components & $\boldsymbol{r}$ & $\boldsymbol{M}$ & $\boldsymbol{S D}$ \\
\hline Identity & $.84^{*}$ & .5 .50 & .1 .68 \\
\hline Object Relations & $.83^{*}$ & $.4,85$ & $.1,75$ \\
\hline Affect Tolerance & $.85^{*}$ & .5 .40 & .1 .59 \\
\hline Affect Regulation & $.86^{*}$ & .4 .91 & .1 .63 \\
\hline Superego Integration & $.80^{*}$ & .6 .22 & .2 .00 \\
\hline Reality Testing & $.90^{*}$ & .6 .84 & .1 .93 \\
\hline Ego Resilience & $.69^{*}$ & .5 .83 & .1 .87 \\
\hline Overall Scale & $.92^{*}$ & .5 .50 & .1 .68 \\
\hline
\end{tabular}

$* \mathrm{p}<.001$ Source: Gordon and Stoffey, 2014.

As we could reveal by the data displayed on literature, we developed a deep research in the Albanian context. It is very important for further studies, to research into differences of the behavioral "restrained" and "direct" trend between the participants from south-east city of Korca and those from north of Shkodra, which also present significant difference in choosing their ideal leadership form. The combination of correlations and overlapping of z-scores for all three categories gave us important indexes over the characteristics of ideal leadership and the prevalence of leadership in Albanian school leaders institutions.

\section{Discussions}

The main aim of this study was to explore the problematic situation of Personality Organization and behavior tendency of Educational Institutions through their leadership style. In the goals of the study was involved either the role of internal and external factors in a healthy behavior Prototype. We have developed a voluminous research in the metanalytical, empirical and situational spectrum and were defined the variables which would be employed in the profound analysis of the present study.

The core variables of the study were as follow:

a. Pathogenic beliefs

b. Relationship with self and the Significant Other

c. Leader behavior in the classroom

d. Leader behavior in the community

e. The impact of the environment on the school leader.

Relating to the main concern of the present article, of this study relating the trending behavior of the educational leaders in Albania, we were based on the first "drive" of Personality organization in the Psychodynamic Manual. The unit for measuring " Maladaptive Behavior 
Tendency "included the following statements: 1, 3, 16, 21, 22, 23, 28, 43, 45, 49, 52, 54, 60, 64, 76 and 77 of the test. Statements related to this element have had obviously a prevailing place over other statements as they carried the greatest weight in the aim of the present study.

Descriptive data revealed an altered medium in our cities. Thus, for instance, in Shkoder, that is located on the North-side of the country, the highest rank (z-score) is achieved in the statement no.67 "When others gaze me, I flush and think..." with a scoring of 1,819, while in Vlora, which is located in the South, at the test for directors of educational institutions, the highest rank is the statement no.35 "I long to expect changes" with a score of 1,44.

Likewise, the lowest rank in Shkoder results in the statement no.21 "I am an anti conformist" with a score of 0,3 whilst in Vlore, the statement no. 6 with a score of 0,04 . There is also a similarity in the assessment ranking between Tirana, as the capital city, and Elbasan, a centeredlocated city. A relatively small portion of respondents $(14 \%)$ expressed a neutral attitude in characterizing behavior (assessed 0 ) whereas the majority of them referred significant differences in behavioral trend.

Longitudinal researches of Tanabaum and Schmidt (1958) revealed that the dependence of leader from the dependent lead to disorganization whereas the freedom of participation for the dependent lead to diffusion of role and breaking boundaries. It is very important for further studies, to research into differences of the behavioral "restrained" and "direct" trend between the south-east city of Korca and the north of Shkodra which also present a significant difference in choosing their ideal leadership form.

It is also suggested for authors that either directors or school teachers to develop collegial relations with a vertical decision making, thus, collecting the opinion of all on the decision of one (1958). All is naturally more than the sum of each of its parts!!

\section{Conclusions}

Research for a Prototypical Identity is of great importance in understanding depthy and prevent difficulties later in life. Finding an identity that could establish a consistent development in prototype represents a long and hard journey for the clinical science. Every category of population is affected at different degrees by stressing events and the psychological and social consequences it provides. The relation with the other object-subject is equally important in defining one's psychological outlook.

Educational leaders are probably the part of the public in Albania least studied in the context of mental health and improvement of psychopathologic parameters for raising efficiency and efficacy not only for the individual but also for the entire society. Their perceptions of personality, behavioral trend and leadership style, are significant for a comprehension of these parameters but also to outline some points from which to develop a strategic middle or long-term plan.

The present study highlight some significant views for the educational system in Albania:

1.School teachers and directors show an increased rate of symptoms for "the maladaptive behavioral tendency" for the conditionality of inner and outer factors.

2.There is a strong relation between pathogenic beliefs of school Leaders and maladaptive behavior as a result of it.

3.It prevails a strong positive correlation between the element of personality and maladaptive behavioral tendency.

Results reveal that a leader with a high level of Neurotic PO, have higher chances for a violent tendency behavior than another with a borderline PO. Thus, individuals with high levels of Neurotic PO should be put in the first line of psychological based intervention. 
Relationship with the significant other, internal mental functioning (M), symptomatic patterns $\mathrm{PO}(\mathrm{P})$ and subjective experience toward these relations $(\mathrm{S})$ are the most powerful predictors of prototype organization and maladaptive behavior.

Research of Fisherbein and Ajzen on the perceptions and concepts (1975) revealed that attitudes and behaviors might change through education.

The results of the present study will help the involved parties, educational system and society to develop a framework for monitoring and implementing them in order to prevent or intervene in the risky or deviant potential situations.

As fore, conducting an ad-hoc working group for translating and adapting the psychodynamic clinical instruments in Albanian language, Implementing a $Q$ methodology in several areas of science and research, studying other affecting variables in the development of Prototype, healthy Personality and Psychological Welfare in society and developing a profound research regarding Personality Organization and Patterns in other areas of Clinical Psychology are the fundamental lines for a structuring and prospective progress in the society.

\section{Acknowledgments:}

For the realization of the present study "The Psychodynamic Prototype of Leadership Styles through the Personality Organization Chart - a neo prospects of $Q$-sort" there have been engaged and have provided their precious contribution many people, researchers, respondents, Ministry of Education and Sports of Albania, Educational Directorates and School Directories of all participating cities and fellows in this present work.

\section{Bibliography}

1. Balint, M., 1936. The final goal of psychoanalytic treatment. International Journal of Psychoanalysis, 17, pp.206-216.

2. Balint, M., 1968. The Basic Fault: Therapeutic Aspects of Regression. London: Tavistock.

3. Blatt, S. J., Auerbach, J. S. and Levy, K. N., 1997. Mental representations in personality development, psychopathology and the therapeutic process. Review of General Psychology, 1(4), pp.351-374.

4. Blatt, S. J., Stayner, D., Auerbach, J. S. and Behrends, R. S., 1996. Change in object and selfrepresentations in long-term, intensive, inpatient treatment of seriously disturbed adolescents and young adults. Psychiatry, 59, pp.82-107. https://doi.org/10.1080/00332747.1996.11024752.

5. Block, J., 1961. The Q- Sort Method in Personality Assessment and Psychiatric Research. Springfield Illinois USA: Charles C. Thomas Publisher.

6. Brown, S.R., 2002. Q Technique and Questionnaires. Operant Subjectivity, 25(2), pp.117-126.

7. Brown, S.R., 1980. Political subjectivity: Applications of $Q$ methodology in political science. New Haven: Yale University Press.

8. Fairbairn, W.R.D., 1952. Psychoanalytic studies of the personality. Oxford, England: Routledge \& Kegan Paul.

9. Fairbairn,W.R.D., 2011. Steps in the Development of an Object-Relation Theory of Personality. British Journal of Medical Psychology, 22(1-2), pp.26-31. https://doi.org/10.1111/j.20448341.1949.tb02880.x

10. Fishbein, M. and Ajzen, I., 1975. Belief, attitude, intention and behavior: An introduction to theory and research. Reading, MA: Addison-Wesley. 
11. Freud, A., 1930. Quattro conferenze di psicoanalisi per insegnanti e genitori [Four psychoanalytic conferences for teachers and parents] In: A. Freud, Scritti, Vol I: 1922-1943. Torino: Boringhieri, 1978.

12. Freud, A., 1960. Psychoanalysis for Teachers, Teachers and Parents-Introductory Lectures, Boston, USA: Beacon Press.

13. Freud, S. 1914. Remembering, repeating and working through (Further Recommendations in the Technique of Psychoanalysis II). S.E., 12, pp.147-156.

14. Gordon, R. M., and Stoffey, R.W 2014. Operationalizing the Psychodynamic Diagnostic Manual: a Preliminary Study of the Psychodiagnostic Chart (PDC). Bulletin of Menninger Clinic, 78(1), pp.1-15. https://doi.org/10.1521/bumc.2014.78.1.1

15. Gordon, R.M, Lingiardi, V., Bornstein, R.F and McWilliams, N, 2015. The Psychodynamic Diagnostic Manual Version 2 (PDM-2): Assessing Patients for Improved Clinical Practice and Research, Psychoanalytic Psychology, 32(1), pp.94-115.

16. Gordon, R.M and Gosgrove, L., 2013. Ethical Considerations in the Development and Application of Mental and Behavioral Nosologies: Lessons from DSM-5. Psychological Injury and Law, 6, pp.330-335.

17. Ibrahimi, S. and Qirajako, E. 2011. Q-sort and the Case-Study Psychoanalysis (unpublished research)

18. Klein, M., 1931. Contributo alla teoria dell'inibizione intellettiva. In: M. Klein, Il nostro mondo adulto e altri saggi (Our adult world and other sages), Italian translation by Alberto Ponsi, G. Martinelli \& C. Firenze, 2002.

19. McKeown, B.F. and Thomas, D.B. 1988. Q methodology. Quantitative Applications in the Social Sciences, Series: Quantitative Applications in the Social Sciences (Book 66), Newbury Park, CA: Sage Publications.

20. Stainton Rogers, R. 1995. Q methodology. In: J.A. Smith, R. Harré, and L. Van Langenhove, eds. Rethinking methods in psychology. London and Thousand Oaks, CA: Sage. pp.178-192.

21. Stephenson, W. 1935. Correlating persons instead of tests. Character and Personality, 4(1), pp.17-24. https://doi.org/10.1111/j.1467-6494.1935.tb02022.x.

22. Tannenbaum, A.S. and Schmidt, W.H, 1958. How to choose a leadership pattern, Harvard Business Review, 36(2), pp.95-105. 